\title{
Pediatric Dental Care in Fanconi Anemia: A Case Report
}

\section{Cuidado dental pediátrico en paciente con anemia de Fanconi: Reporte de un caso}

César Gaitán-Fonseca DDS, MSc, PhD¹; Maribel Frías-Muñoz DDS²; Luis Enrique Guerrero-de la Torre DDS3; Obed Lemus-Rojero DDS, MSc ${ }^{4}$; Luis Alejandro Aguilera-Galavíz DDS, MSc, PhD³

1. Professor-Investigador, Posgrado Estomatología Pediátrica, Unidad Académica de Odontología, Universidad Autónoma de Zacatecas "Francisco García Salinas", Mexico.

2. Resident, Posgrado en Estomatología Pediátrica, Universidad Autónoma de Zacatecas "Francisco García Salinas", Mexico.

3. Professor-Investigador, Maestría en Ciencias Biomédicas, Área Ciencias de la Salud, Universidad Autónoma de Zacatecas "Francisco García Salinas", Mexico.

4. Professor-Investigador, Diagnóstico en Patología y Medicina Bucal, Unidad Académica de Odontología, Universidad Autónoma de Zacatecas "Francisco García Salinas", Mexico.

Correspondence to: Dr. Luis Alejandro Aguilera-Galavíz - luisgalaviz_65@hotmail.com

Received: 2-II-2018

Accepted: 10-V-2018

Published Online First: 18-V-2018

DOI: https://doi.org/10.15517/ijds.v0i0.33350

\section{ABSTRACT}

Fanconi Anemia (FA) is an autosomal-recessive genetic disease that is linked to Chromosome $X$, which is reported in studies with pancytopenia, congenital malformations, and a predisposition to develop cancer. FA 1,360,000 births, and is a condition that occurs in heterozygous subjects in $0.5 \%$ of the population. In Mexico, there are, to our knowledge, no epidemiological data on FA, and it is thought that many cases are underdiagnosed. This document reports the clinical case of a patient diagnosed with FA who the cardinal signs of this rare pathology. The pediatric approach involved was performed with a preventive and restorative approach, in addition to the design and placement of a palatal shutter. After a follow-up of more than 12 months, a significant reduction in the recurrence of infections, such as otitis, tonsillitis, and pharyngitis, was observed, suggesting a positive influence of the use of the obturator. In turn with the latter, there was a lower need for transfusions, which may also be related to control of the foci of the infection. The pediatric approach employed in to patients with FA may have significant repercussions on both quality of life and on their patients' general systemic condition, although this is scarcely verifiable due to the rarity of this pathology.

\section{KEYWORDS}

Fanconi anemia; Diagnosis; Treatment; Pediatric dentistry. 


\section{RESUMEN}

La anemia de Fanconi es una enfermedad genética, autosómica recesiva, ligada al cromosoma $X$, la cual cursa con pancitopenia, malformaciones congénitas y predisposición a desarrollar cáncer. Afecta a 1:360,000 nacimientos, es un padecimiento que se presenta en sujetos heterocigotos en el $0.5 \%$ de la población, en México no existen datos epidemiológicos y se cree que muchos casos se encuentran sub diagnosticados. En el presente documento se reporta el caso clínico de una paciente con diagnóstico de Anemia de Fanconi, que presenta los signos cardinales de esta rara patología. Se realizó el abordaje odontopediátrico con un enfoque preventivo y restaurador, además del diseño y colocación de un obturador palatino. Tras un seguimiento mayor a 12 meses se logró observar una reducción importante en la recurrencia de infecciones como otitis, amigdalitis y faringitis, lo que sugiere una influencia positiva del uso del obturador, y a su vez se pudo constatar una menor necesidad de transfusiones, lo cual puede también estar relacionado con el control de los focos de infección. El abordaje odontopediátrico dirigido a pacientes con Anemia de Fanconi puede tener repercusiones importantes tanto en la calidad de vida como en su condición sistémica general, aunque esto es difícilmente comprobable debido la rareza de dicha patología.

\section{PALABRAS CLAVE}

Anemia de Fanconi; Diagnóstico; Tratamiento; Odontología pediátrica.

\section{INTRODUCTION}

Fanconi Anemia (FA) is a rare multisystem genetic disorder that presents signs and symptoms including bone-marrow failure, somatic malformations, pancytopenia, and a predisposition to cancer, primarily acute myeloid leukemia and epithelial cancers of the head and neck (1). FAfollows an unfavorable course through deterioration of blood parameters and hematological malignization. The use of corticosteroids and androgens provide a partial answer to these hematological complications; however, transfusions and antiinfective therapies are necessary. Curative and definitive treatment in these patients comprises bone-marrow transplantation $(2,3)$.

FA is more frequent aplastic anemia in childhood. A total of 1:360,000 births in the population is affected. There are currently over 1,000 documented cases in the world; the male:female ratio is $3: 1$. Average age of diagnosis is 8 years and the average age of death is approximately 13 years $(4,7)$.

The general diagnosis of FA is based on a cytogenetic diagnosis by means of DiEpoxiButane (DEB) and molecular genetic diagnosis. The differential diagnosis is associated with characteristic related with radial axis, medullar aplasia, and growth disorder. Clinical characteristics are related with skin, growth, craniofacial disorder, and skeletal disorder, kidney and urinary tract, genital, cardiological, gastrointestinal, central nervous system, hematologic, cancer, and functional characteristics $(1,6)$.

FA is a rare entity and, on the other hand, its clinical, personal, and familial diagnosis and management is complicated. The importance of contributing in terms of diagnosis, control, and the restitution of general and systemic health depends on a multidisciplinary team. Pediatric-Dentistry personnel can sometimes be the first to have contact with this patient. Pediatric Dentists can 
detect or suspect some abnormal pathology in the he oral cavity that can contribute to diagnosis and health restoration (8). When a patient is diagnosed and requests oral care, Pediatric Dentistry plays an important role. FA can presents hematological diseases that complicate the patient's systemic and dental care and can increase and control hematological values. The aim of this case report was to provide basic dental guidelines in the management of pediatric patients with FA, principally directed toward Pediatric-Dentistry personnel.

\section{CASE REPORT}

A female patient 4 years of age (2014) with a diagnosis of FA (human karyotype) and 22 hospital admissions due to her treatment for FA, with a blood transfusion and palatoplasty, was referred for oral examination at the Pediatric Clinic of the University of Zacatecas. In the patient's clinical file, the parents referred that she was a second, 36-week pregnancy. Anemia and cleft palatal $(6,7,8$ of the Stark and Kernahan Classification) were presented at birth and 1 month later, a palatal obturator was installed and the patient presents onychophagy at present. Size of $11 \mathrm{~cm}$, weight of $19 \mathrm{~kg}$, and cephalic circumference of $53 \mathrm{~cm}$ were presented on anthropometric examination. To rule out genetic antecedents, the mother was subjected to human karyotype (was negative to FA) and the dad refused to have this evaluation. The principal problem and reason for consultation was cleft palate, difficulty in eating, and recurrent complications of the systemic health of the patient.

\section{EXTRA-ORAL EXAMINATION}

The nasal bridge is long, while the column is short. The upper lip is thick, large, continuous, full, hydrated, pale in color, while the lower lip is slender with functional mobility. The facial midline coincides with the sagittal plane, the chin being retruded with reference to the maxilla, and the ears presenting low implantation with reference to the convex interpupillary-line profile, and there is a lack of facial proportion in that the lower third is observed as decreased with respect to the upper two thirds. Facial type is Mesoproscopic (Figure 1).

\section{INTRAORAL EXAMINATION}

The softtissuespresentnormal characteristics, while the hard palate presents a palatal fissure posterior to palaplasties. Then patient presents caries 3/2 according to the ICDAS classification in dental organs 74 and 75 , anterior cross. Bite and mandibular retrussion, hyper. Nasalization, and nasal breathing. Primordial space present in the upper arch, dental midline, if it coincides with the facial midline, a canine relationship: Class III, terminal plane: mesial exaggerated, over-horizontal bite: $3 \mathrm{~mm}$, over-vertical bite: $3 / 3$, and cross-bite of dental organs 51, 61, and 62 (Figure 1).

Due to that prognosis was reserved because of damage in multiple systems of the patient's body, bone-marrow transplantation cannot be carried out due to the patient's physical conditions, as well as to that there is no donor compatible with a transplantation to date. Hematological pediatric control (January to December, 2014) with platelet, hemoglobin, and hematic biometrics were measured in the patient throughout the entire Pediatric-Dentistry treatment. In Table I, hemoglobin control is shown asunder normal parameters. Even with the increased values after transfusion, the hemoglobin did not increase to normal parameters as an effect of the hemolytic activity. In the other hand, an important risk factor comprises the platelet concentration; as can be observed, the values that were observed were found to be under normal parameters, clinically represented by bruises or coagulation alterations, the patient presenting low weight and physical activity (Table II). In Table III, the correlation of the red blood cells, hemoglobin, and hematocrit clearly 
reveals the anemic condition in every measurement, and the hemolytic activity was present throughout the year.

In the dental-treatment plan, different procedures were included as follows: elaboration of the clinical file: the ordering extra $x$-xray series (orthopantomography and lateral skull) (1/2014); the Fones brushing technique (2/2014); the TRA technique in $\operatorname{OD} 74$, and 75 (3/2014); sealant fissure in 55 and 85, and restoration with a glass ionomer (Ketac Molarß) (4/2014). A print of the shutter plate was made, a passive palatal obturator was set in place, and instructions were provided for its care and use (Figure 2). At the beginning of this of this placement, there were better conditions reflected in the general health of the patient (5/2014). Control of the patient was performed in December 2014 at the Pediatric Clinic. In 2015, the patient had a relapse in her systemic health. The parents had sent for a determination of bone-marrow transplantation at IMMS, México (11/23/2016). The patient was admitted to the Pediatric Hematologic Department (12/14/2016) for post-transplantation control and discharge (12/22/2016) without complications and prophylactic medication.
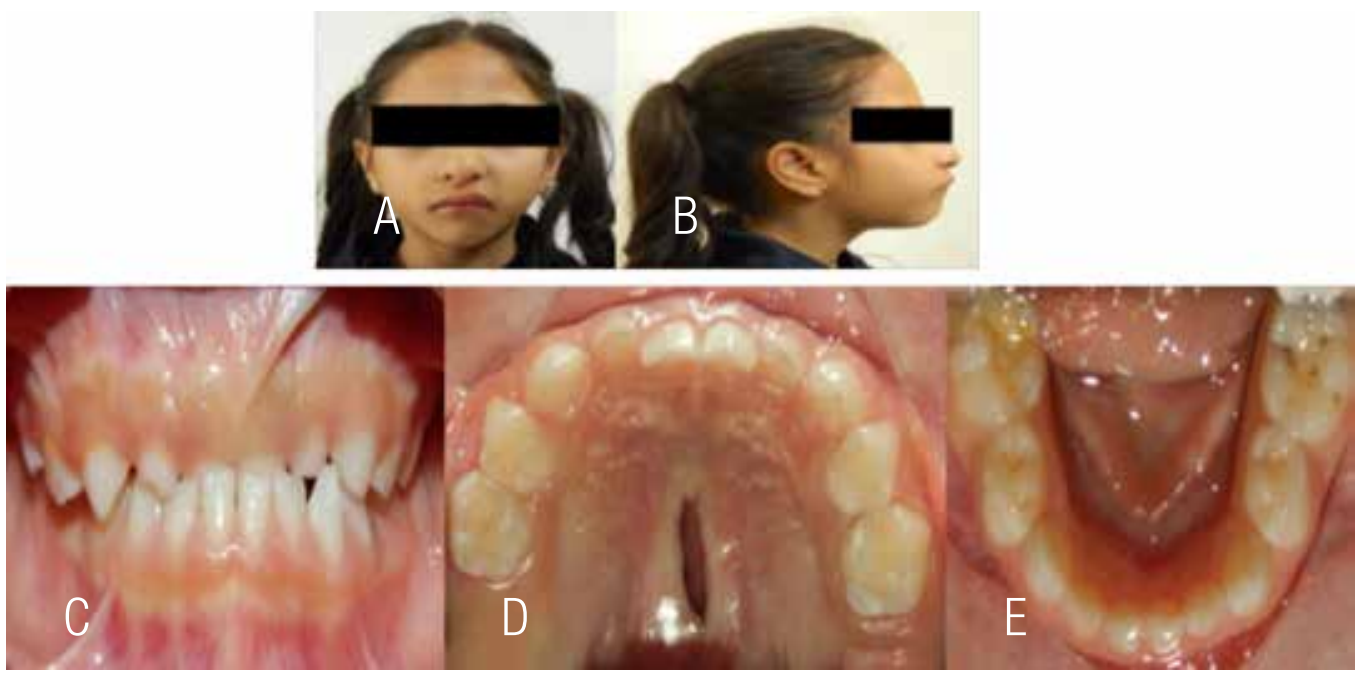

Figure 1. Extra- and intraoral examination $A$ : present frontal characteristics of the patient, $B$ : a lateral profile shows facial mesoprosopic type, C: showed malocclusion class III, D: a palatal fissure, E: presence of caries in some dental pieces.

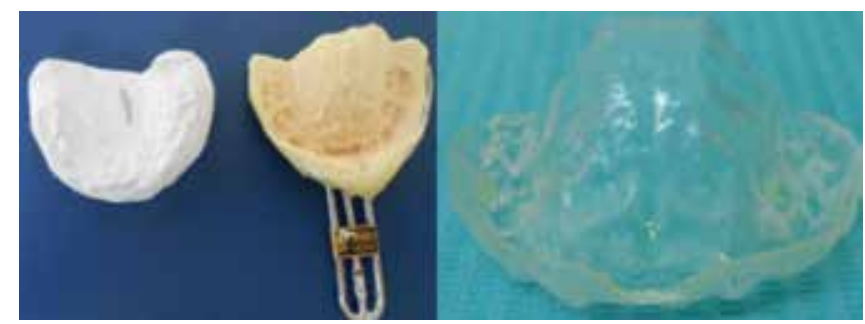

Figure 2. Palatal obturator, an impression, and palatal obturator were created to increase nutrition and blood values in the patient. 
Table I. Hemoglobin control.
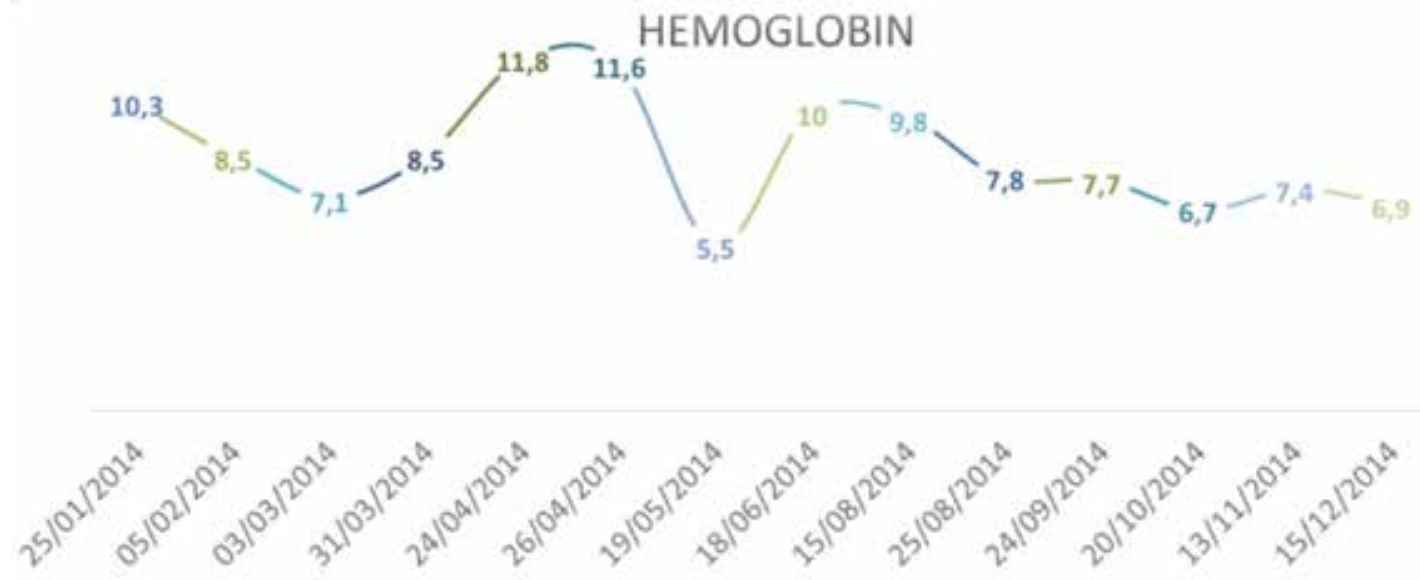

Table II. Platelet control.
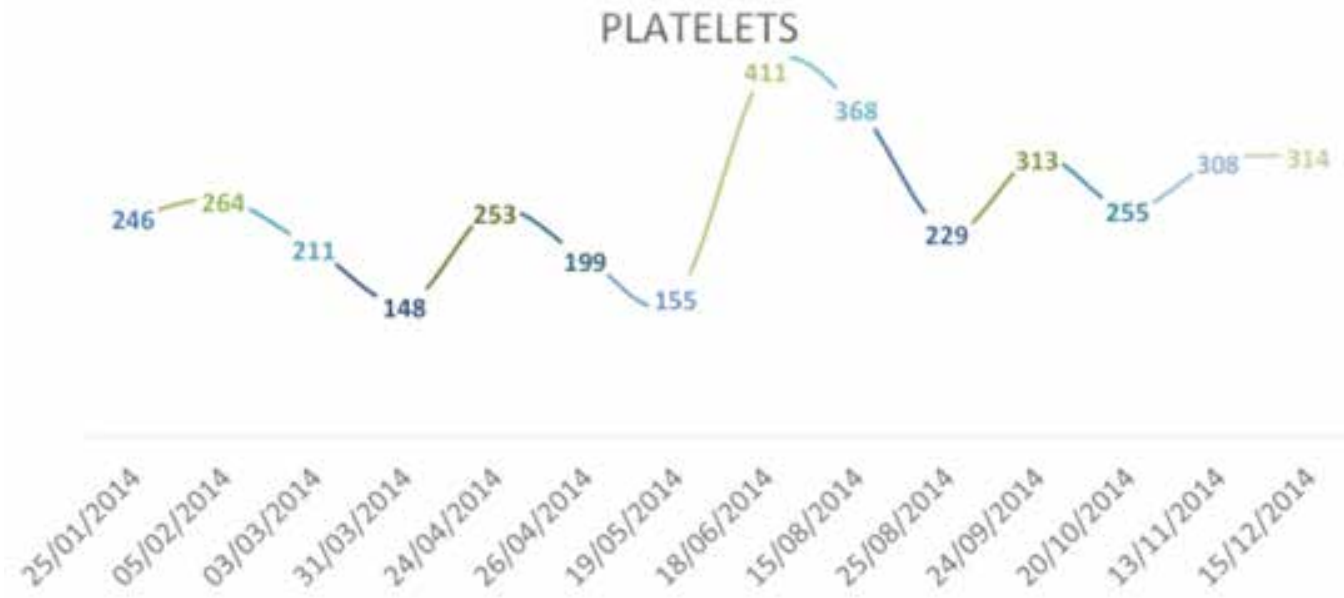

Table III. Blood count.

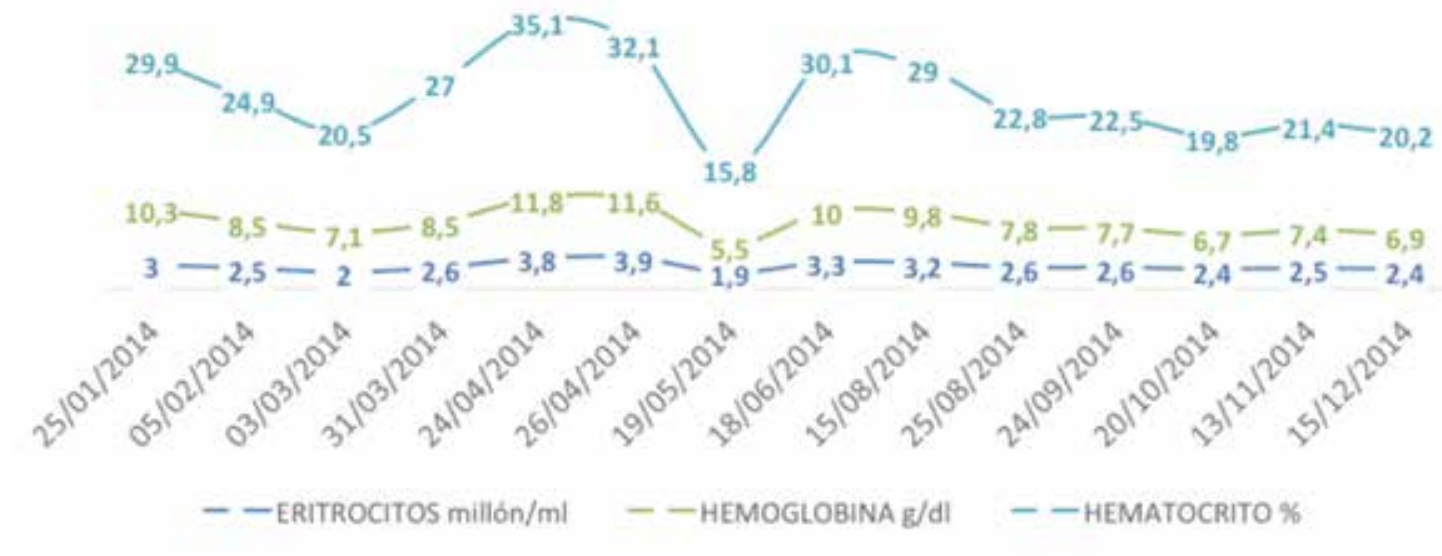

ERITROCITOS $=$ ERYTHROCYTES. HEMLOGLOBINA $=$ HEMOGLOBIN. HEMATOCRITO $=$ HEMATOCRIT 


\section{DISCUSSION AND CONCLUSION}

Fanconi anemia is a rare autosomal recessive disease characterized by various congenital anomalies. The most significant feature of FA is progressive bone-marrow failure, which leads to aplastic anemia and myelodysplastic syndrome, usually during childhood. Hematologic alterations develop in virtually all patients with FA at a median age of 7 years. Hematopoietic StemCell Transplantation (HSCT) is the only curative treatment, to our knowledge, which can restore normal hematopoiesis (9).

Between $60 \%$ and $75 \%$ of patients with FA have congenital defects, such as short stature, microcephaly, endocrine problems, pigmentation of the skin in the form of brown-milk spots, petechiae, and contusions, infections, and developmental disabilities, abnormalities of the skin, arms, head, eyes, kidneys, and ears. Hematologic complications progressively include increased pancytopenia, anemia, thrombocytopenia, leukopenia, macrocytosis, and fetal erythropoiesis. Oral manifestations can range from dental agenesis, supernumerary teeth, small teeth, abnormal roots, dental malformations, positioned teeth, dental caries, gingivitis, periodontal disease, oral mucosal lesions, and dysfunction of the salivary glands, to predisposition to develop oral cancers, such as Squamous Cell Carcinoma (SCC) (10).

According to the background, the pediatric follow-up, the data obtained from this patient with $F A$, and the natural history of the disease presented in this particular patient, the requirement of blood products, especially of the hemotransfusional type performed monthly to maintain a stable hemoglobin count and, in addition to the platelet count since the beginning of the patient's dental treatment, it can be observed that, toward month 5 of t pediatricdental care, a palatal obturator was set in place prior to testing by clinical examination and laboratories without infection of palatine, amygdalin, optic, or any head or neck infection related to the palatine fistula presented by the patient, a very slow decrease in hemoglobin was observed in the first 2 months after insertion of the obturator, reducing the need for hemotransfusion during these months. In terms of the platelet count, the patient presented a significant increase in the latter. On the other, hand this obturator contributed to the decreased accumulation and communication of food remains in the fistula; however, it is noteworthy that the obturator was only used for 2 months since the patient presented discomfort in the palate due to growth and physiological development. The need for hemotransfusion required monthly restoration, due to that it underwent its own treatment for kidney disease with hospital management (10-12).

Pediatric Dentists are an important part of the patient's management, in that they can establish a preventive protocol to improve oral conditions, which will increase the patient's quality of life and health level. When the case presents, a curative treatment can be carried out, always with full knowledge of its limitations and the inclusion of under which conditions the different dental procedures can be performed.

\section{CONSENT}

Written informed consent was obtained from the patient's parent for publication of this case report and accompanying images. 


\section{REFERENCES}

1. Dufour C. How I manage patients with Fanconi anaemia. Br J Haematol 2017; 178 (1): 32-47.

2. D'agulham D., Chaiben L., Lima A., TorresPereira C., Machado M. Fanconi anemia: main oral manifestations. RGO, Rev Gaúch Odontol 2014; 62 (3): 281-288.

3. Wassenhov L., Mochly-Rosen D., Weinberg K. Aldehyde dehydrogenase 2 in aplastic anemia Fanconi anemia and hematopoietic stem cells. Mol Genet Metab 2016; 119 (1): 28-36.

4. Kutler D., Auerbach A. Fanconi anemia in Ashkenazi Jews. Fam Cancer 2014; 3 (3-4): 241-248.

5. Tipping A., Pearson T., Morgan N., Gibson R., Kuyt L., Havenga C., Gluckman E., Joenje H., de Ravel T., Jansen S., Mathew C. Molecular and genealogical evidence for a founder effect in Fanconi anemia families of the Afrikaner population of South Africa. Proc Natl Acad Sci U S A 2001; 98 (10): 5734-5739.

6. Salem A., El-Bassyouni H., El-Kamah G., Zarouk W., Eid M., Mosaad R., Sayed A., Temtamy S. Screening for common mutations in four FANCA gene exons in Egyptian Fanconi anemia patients. Genes Dis 2014; 3 (1): 24-30.

7. Callén E., Casado J., Tischkowitz M., Bueren J., Creus A., Marcos R., Dasí A., Estella J.,
Muñoz A., Ortega J., de Winter J., Joenje H., Schindler D., Hanenberg H., Hodgson S., Mathew C., Surrallés J. A common founder mutation in FANCA underlies the world's highest prevalence of Fanconi anemia in Gypsy families from Spain. Blood 2005; 5 (105): 1946-1949.

8. Cavalcanti L., Araújo R., Bonfim C., TorresPereira C. Oral manifestations compatible with chronic graft-versus-host disease in patients with Fanconi anemia Biol Blood Marrow Transplant 2015; 21 (2): 275-280.

9. Masserot C., Peffault R., Rocha V., Leblanc T., Rigolet A., Pascal F., Socié G. Head and neck squamous cell carcinoma in 13 patients with Fanconi anemia after hematopoietic stem cell transplantation. Cancer 2008; 113 (12): 3315-3322.

10. Goswami M., Bhushan U., Goswami M. Dental perspective of rare disease of Fanconi anemia: case report with review. Clin Med Insights Case Rep 2016; 9: 25-30.

11. Lyko K., Lemes A. L., Bonfim C., TorresPereira C. C., Amenábar J. M. Oral health status in children and adolescents with Fanconi anemia. Spec Care Dentist 2016; 36 (2): 71-74.

12. Engel J. D., Ruskin J. D., Tu H. K. Hematologic management of a patient with Fanconi's anemia undergoing bone grafting and implant surgery. J Oral Maxillofac Surg 1992; 50 (3): 288-292. 